ORIGINAL PROF-2137

\title{
GUILLAIN BARRE SYNDROME;
}

\section{Clinical feature in children}

\section{Dr. Sohail Ashraf, Dr. Arshalooz J. Rahman.}

ABSTRACT...Background: Guillian Barre Syndrome is a polyradiculopathy characterized by symmetric ascending paralysis and areflexia. It affects all age groups and both sexes with an unpredictable outcome. Objectives: The aims of this study were to identify the various diseases presenting as Acute Flaccid Paralysis and notice clinical features and outcome of cases of Guillian Barre Syndrome. Materials and Methods: Retrospective analysis of 53 patients presenting as Acute Flaccid Paralysis was done. Clinical features and laboratory investigations of 39 patients of Guillian Barre syndrome were reviewed. Results: Among all cases of Acute Flaccid Paralysis, Guillian Barre syndrome formed the bulk of the cases (73.6\%).It was more common in females and in age group of 10 years or below. In majority of the cases, rapid onset of weakness was the initial symptom. Mortality was $100 \%$ in patients who had respiratory muscle involvement and who required mechanical ventilation. Conclusions: In our study the main factor causing death in a case of Guillian Barre syndrome was bulbar involvement requiring mechanical ventilation. Early recognition of the prognostic factors may lead to decreased mortality in case of Guillian Barre syndrome.

Key words: Guillian Barre syndrome, AFP, Mechanical ventilation.

Article Citation

Ashraf S, Rahman AJ. Guillain Barre Syndrome; Clinical feature in children. Professional Med J 2013;20(3): 348-353.

\section{INTRODUCTION}

Acute Flaccid Paralysis (AFP) is defined as "Any child $<15$ years of age with acute (rapid progression), flaccid paralysis including Guillain Barre Syndrome (GBS) or any flaccid paralysis illness at any age when polio is suspected". Since the launch of Global Polio Eradication Initiative in 1998 by World Health Organization, the number of cases of polio has decreased all over the world. In 2012, only three countries in the world namely Pakistan, Afghanistan and Nigeria remain polio-endemic ${ }^{1}$.

GBS is an immune mediated acute polyradiculoneuropathy and one of common causes of AFP in pediatric population after poliomyelitis ${ }^{2}$.GBS leads to a wide variety of deficits but the most common presentations are sudden onset of ascending paralysis, muscle pain and areflexia. Sensory, autonomic, and brainstem abnormalities may also be $\operatorname{seen}^{3}$. It affects both genders and the annual incidence is reported to be ranging from 0.34 to $2.1 / 100,000^{4,5}$. The various antibodies that have been implicated in the pathogenesis of GBS are antibodies to GM1, GM1b, GD1a, GalNac-GD1a and GQ1b ${ }^{6}$. Several infections e.g., Epstein-Barr virus, cytomegalovirus, hepatitis, varicella, other herpes viruses, Mycoplasma pneumoniae, Clostridium jejuni as well as immunizations have been known to precede or to be associated with the illness. $C$ jejuni seems to be the most commonly described pathogen associated with $\mathrm{GBS}^{7}$. There are various variants of GBS like acute inflammatory demyelinating polyneuropathy (AIDP), acute motor axonal neuropathy (AMAN), acute motor sensory axonal neuropathy (AMSAN) and the Miller Fisher syndrome(MFS).

The prognosis of GBS is generally favorable with a mortality ranging from $10 \%$ to $20 \%{ }^{9}$. Results of trials have shown equivalent efficacy of both plasma exchange and intravenous immunoglobulin (IVIG) in hastening recovery from Guillain Barre syndrome ${ }^{10}$. Although use of IVIG before loss of unaided walking has shown faster recovery in one of the trial ${ }^{11}$. Respiratory failure is one of the mot important complication of GBS resulting in need for mechanical ventilation and leading to mortality ${ }^{12}$. There is limited data on the factors causing mortality in pediatric cases of GBS in Pakistan; therefore the aims of this study 
were to ascertain the causes of AFP cases and to review the clinical course and identify various factors causing mortality in patients with Guillain Barre Syndrome admitted to a tertiary care hospital.

\section{MATERIAL AND METHOD}

A retrospective study was carried out in the Pediatric department of Liaquat National Hospital, which is a 750 bedded, tertiary care hospital. Data of all the cases of AFP who were admitted from August 2000 to August 2008 in the pediatric department was analyzed. A case of AFP was defined as "a child aged less than 15 years of age with acute onset of flaccid paralysis in one or more limb or acute onset of bulbar paralysis". Records of all of the AFP cases were evaluated regarding history, clinical examination, cerebrospinal fluid (CSF) exam and Nerve conduction velocity (NCV). Stool sample analysis for polio virus was also recorded. The diagnostic criteria of GBS included motor weakness, progression of weakness, relative symmetry, sensory signs and symptoms and laboratory criteria such as increased protein in CSF and electro diagnostic features such as nerve conduction slowing or blockage. A structured questionnaire was designed which documented variables like diagnosis of the case, age, sex of the child, symptoms and their duration before coming to hospital, history of fever, pattern of weakness, involvement of cranial nerves, respiratory muscle and swallowing muscle were noted. Only IVIG was given as specific treatment to all of the cases of GBS along with other supporting measures such as Intake/output charting, vitals monitoring and intravenous fluid therapy. Data was also analyzed for the requirement of mechanical ventilator and its outcome. Analysis was done using the Statistical package for social science (SPSS 15.0). The results were expressed as percentage.

\section{RESULTS}

Total number of cases of acute flaccid paralysis reported from August 2000 to August 2008 were 53, out of which. 27 (51\%) were male and 26 (49\%) were female. Majority i.e. 39 cases (73.6 \%) were diagnosed as Guillain Barre Syndrome, 4 as Transverse Myelitis while only one case was confirmed as case of Poliomyelitis. Frequencies of other diseases presenting as AFP are given in (Table-I). 49 out of 53 cases of AFP were discharged home while 4 patients of GBS expired during treatment in the hospital. Examination at 60th day after the illness showed that $11(20.8 \%)$ patients still had residual paralysis whereas it was absent in 31 (58.5\%) patients and 7 patients were lost to follow up.

\begin{tabular}{|l|c|c|}
\hline Clinical Diagnosis (N-53) & Frequency & Percent \\
\hline Guillain Barre Syndrome & 39 & 73.6 \\
\hline Transverse Myelitis & 4 & 7.5 \\
\hline Traumatic Neuritis & 3 & 5.7 \\
\hline Myositis & 3 & 5.7 \\
\hline Poliomyelitis & 1 & 1.9 \\
\hline Septic Arthritis & 1 & 1.9 \\
\hline Hemiplegia of Childhood & 1 & 1.9 \\
\hline Familial periodic paralysis & 1 & 1.9 \\
\hline \multicolumn{2}{|r|}{ Table-I. Cases presenting as AFP } \\
\hline
\end{tabular}

Out of 39 patients of GBS, 18 were male and 21 were female with a male/female ratio of 0.8:1. Majority of the patient were of age 10 or below i.e. 31 (79.4\%) and only 08 patients were of age 11 or above. 29 patients (74\%) were admitted in the hospital within 6 days of development of symptoms whereas 7 patients had symptom duration ranging between 7 to 14 days and 3 patients had duration lasting for more than 2 weeks before coming to the hospital. History of fever was present in 17 patients (43.5\%), Flu in 4 and diarrhea in only 1 patient. Majority $(71.7 \%)$ had rapid onset of weakness. Most common neuromuscular problem at the time of admission was muscle weakness and inability to walk followed by muscle pain. Three 
patients had facial nerve palsy. Respiratory and swallowing muscles were involved in 4 patients who later required mechanical ventilation also. (Table II)

\begin{tabular}{|c|c|c|}
\hline Variables & Frequency & Percent \\
\hline \multicolumn{3}{|l|}{ Age } \\
\hline $1-5$ years & 16 & 41 \\
\hline $6-10$ years & 15 & 38.4 \\
\hline$>11$ years & 08 & 20.5 \\
\hline \multicolumn{3}{|l|}{ Sex } \\
\hline Male & 18 & 46 \\
\hline Female & 21 & 53.8 \\
\hline \multicolumn{3}{|l|}{$\begin{array}{l}\text { Duration of symptoms before } \\
\text { coming to hospital }\end{array}$} \\
\hline 1-6 days & 29 & 74.3 \\
\hline 7-14 days & 07 & 17.9 \\
\hline$>2 w k s$ & 03 & 7.69 \\
\hline \multicolumn{3}{|l|}{ Preceding history of fever } \\
\hline Present & 17 & 43.5 \\
\hline Not present & 22 & 56.4 \\
\hline \multicolumn{3}{|l|}{ Presenting symptom } \\
\hline Muscle weakness/Inability to walk & 16 & 41 \\
\hline Muscle Pain & 12 & 30.7 \\
\hline Cranial nerve abnormality & 03 & 7.69 \\
\hline Difficulty in breathing & 04 & 10.25 \\
\hline Difficulty in swallowing & 04 & 10.25 \\
\hline \multicolumn{3}{|l|}{ Onset of Weakness } \\
\hline Rapid & 28 & 71.7 \\
\hline Gradual & 11 & 28.2 \\
\hline
\end{tabular}

Table-II. Clinical features of GBS patients

Review of the data shows that mortality was high among males (11.1\%) as compared to females (9.5\%) and in children between ages 6-10 yrs (20\%) compared to children with age less than 6 years $(6.25 \%)$ and none of the patient above 10 years of age expired. Mortality was $100 \%$ in the patients who required mechanical ventilation and in patients with respiratory and swallowing muscle involvement. Higher mortality rate was seen in patients who were admitted in the hospital in the 2nd week after development of symptoms in comparison to the patients who were admitted within a week or who were admitted $>2$ week after the onset of the symptoms. None of the patient with cranial nerve abnormality expired. Similarly patients with history of fever before admission and rapid onset of the muscle weakness also had higher mortality rates as shown in Table-III.

\begin{tabular}{|l|c|c|}
\hline \multicolumn{1}{|c|}{ Variable } & Discharge & Expired(\%) \\
\hline Age: & 15 & $1(6.25)$ \\
1-5 years (N-16) & 12 & $3(20)$ \\
6-10 years (N-15) & 08 & $0(0)$ \\
> 11 years (N-08) & & \\
\hline Sex: & 16 & $02(11.1)$ \\
Male (N-18) & 19 & $02(9.5)$ \\
Female (N-21) & & \\
\hline Duration of symptoms before & & \\
coming to hospital: & 26 & $03(10.3)$ \\
1-6 day (N-29) & 06 & $01(14.2)$ \\
7-14 day (N-07) & 03 & $0(0)$ \\
> 2 wks (N-03) & & \\
\hline Preceding history of fever: & 15 & $2(11.76$ \\
Present (N-17) & 20 & $02(9.09)$ \\
Not present (N-22) & & \\
\hline Onset of weakness: & 24 & $03(11.11)$ \\
Rapid (N-28) & 10 & $01(9.09)$ \\
Gradual (N-11) & & \\
\hline Cranial never: & 0 & $04(100)$ \\
Normal (N-36) & 35 & $0(0)$ \\
Involved (N-03) & 35 & $04(0)$ \\
\hline Respiratory muscle: & & $04(100)$ \\
Involved (N-04) & & $0(0)$ \\
Not involved (N-35) & & \\
\hline Swallowing muscle: & & \\
Involved (N-04) & & $0400)$ \\
Not involved (N-35) & & \\
\hline Ventilator: & & \\
Required (N-04) & & \\
Not required (N-35) & & \\
& & \\
\hline
\end{tabular}

Table-III. Outcome of GBS patients

\section{DISCUSSION}

With the marked decline in incidence of Poliomyelitis in other parts of the world, GBS is now considered as one 
of the important and common cause of AFP. Its incidence varies from one region to another. In our study it accounted for $73.6 \%$ of all AFP cases which is comparatively high when compared to previous Pakistani $^{13}$ and Bangladesh ${ }^{14}$ studies which showed frequency of $47.29 \%$ and $47.1 \%$ respectively but in accordance with a western study where it was present in $72.2 \%$ of cases $^{15}$. It has been reported in both of the genders but predominance was seen in females in our study and in a previous local data ${ }^{13}$ which is different from male predominance reported in the German ${ }^{16}$ and American studies ${ }^{15}$. It's incidence was found to be high in younger children ( $<6$ years) which is in consistence with the earlier studies ${ }^{13,15}$.

GBS is an immune mediated polyradiculopathy presenting in various forms. Risk of GBS after vaccination may be slightly higher than general population. Prior infection is well established as a precipitating event in the development of GBS. It is frequently associated with history of 1-4 weeks preceding illness such as upper respiratory tract infection or acute enterocolitis. The most common neuromuscular symptoms present at the time of presentation to hospital are muscle weakness ${ }^{17,18}$, inability to walk and myalgias ${ }^{19}$ which were also present in our patients. In our study, cranial nerve involvement was present in only $7.69 \%$ of cases whereas Koul ${ }^{20}$ and Korinthenberg ${ }^{16}$ found involvement in about $50 \%$ of the cases in their respective studies. Facial weakness is most common followed by abducens palsy which causes ophthalmoparesis. Respiratory muscle involvement often in association with cardiac arrhythmias and dysautonomia has been found to be associated with mortality in GBS. Therefore meticulous respiratory care and early recognition of bulbar weakness can reduce the mortality. Respiratory dysfunction due to diaphragmatic weakness is common in patients with severe quadriparesis.

Patients with weakness of neck muscles, tongue and palate often have concomitant diaphragmatic and respiratory muscle involvement. We found respiratory muscle impairment leading to mechanical ventilation in only 4 patients $(10.25 \%)$ which is low as compared to other western ${ }^{21}$ and Asian $^{20}$ studies which had involvement ranging from 15 to $17 \%$.

GBS has an unpredictable course and optimal management and treatment of GBS is important as the chances of full recovery are high if the patient overcomes the acute stage. Generally the outcome of GBS is more favorable in children than in adults. Deaths are relatively rare, especially if the disorder is diagnosed and treated early. However, the recovery period is long, often weeks to months. Mortality rate in our study was $10.25 \%$ which is high as compared to $2.85 \%{ }^{13}$ and $5 \%{ }^{15}$ reported by other researchers. There is paucity of local pediatric data regarding various prognostic factors of GBS although few combined pediatric and adult studies have been done in this regard. The factors associated with $100 \%$ mortality in our study were respiratory muscle impairment and mechanical ventilation which is similar to the adult studies by Gohar ${ }^{22}$ and Sundar ${ }^{23}$.

We would recommend to do more pediatric studies with larger sample size regarding the prognostic factors of GBS and also to include other variables like relation to different treatment modalities, types of GBS etc to its mortality.

\section{CONCLUSIONS}

GBS is a leading cause of AFP commonly presenting as muscular weakness and inability to walk. Involvement of respiratory and swallowing muscles in GBS is associated with requirement for mechanical ventilation and can result in high mortality rate.

\section{Copyright $\Subset 15$ Feb, 2013.}

\section{REFERENCES}

1. WHO/poliomyelitis. Mediacentre-factsheet [Online] Oct 2012. [Cited 2012 Nov 20]. Available from www.who.int/mediacentre/factsheets/fs114/en/. 
2. Nachamkin I, Arzarte Barbosa P, Ung H, Lobato C, Gonzalez Rivera A, Rodriguez P, et al. Patterns of Guillain-Barre syndrome in children: results from a Mexican population. Neurology. 2007 Oct 23;69 (17):1665-71.

3. Avila-Funes JA, Mariona-Montero VA, Melano-Carranza E. [Guillain-Barre syndrome: etiology and pathogenesis] Rev Invest Clin. 2002 JulAug;54(4):357-63.

4. McGrogan A, Madle GC, Seaman HE, de Vries CS. The epidemiology of Guillain-Barré syndrome worldwide. A systematic literature review. Neuroepidemiology. 2009;32(2):150-63.

5. Deceuninck G, Boucher RM, De Wals P, Ouakki M. Epidemiology of Guillain-Barré syndrome in the province of Quebec. Can J Neurol Sci. 2008 Sep;35 (4):472-5

6. Hughes RA, Cornblath DR. Guillain-Barré syndrome. Lancet. 2005 Nov 5;366(9497):1653-66.

7. Kuwabara S. Guillain Barre syndrome: epidemiology, pathophyiology and management. Drugs 2004;64 (6):597-610

8. Pascual-Pascual SI. Recent aspects of acute and chronic inflammatory polyneuropathies: GuillainBarré syndrome and chronic inflammatory demyelinating polyneuropathy Rev Neurol 2002 Aug 1-15;35(3):269-76.

9. Erazo Torricelli R. Guillain Barré syndrome in pediatrics Medicina (B Aires). 2009; 69(1):84-91.

10. Hughes RA, Raphael JC, Swan AV, van Doorn PA. Intravenous immunoglobulin for Guillain-Barre syndrome. Cochrane Database Syst Rev. 2006 Jan 25;(1):CD002063.

11. Korinthenberg R, Schessl J, Kirschner J, Mönting JS. Intravenously administered immunoglobulin in the treatment of childhood Guillain-Barré syndrome: a randomized trial. Pediatrics. $2005 \mathrm{Jul} ; 116(1): 8-14$.

12. Orlikowski D, Prigent H, Sharshar T, Lofaso F, Raphael JC. Respiratory dysfunction in Guillain-Barré Syndrome. Neurocrit Care. 2004;1(4):415-22.
13. Anis-ur-Rehman, Idris M, Elahi M, Jamshed, Arif A. 1 Guillain Barre syndrome: the leading cause of acute flaccid paralysis in Hazara division. J Ayub Med Coll Abbottabad. 2007 Jan-Mar;19(1):26-8.

14. Rasul CH, Das PL, Alam S, Ahmed S, Ahmed M. Clinical profile of acute flaccid paralysis. Med $\mathrm{J}$ Malaysia. 2002 Mar;57(1):61-5.

15. Molinero MR, Varon D, Holden KR, Sladky JT, Molina IB, Cleaves F. Epidemiology of childhood Guillain-Barré syndrome as a cause of acute flaccid paralysis in Honduras: 1989-1999.1 J Child Neurol. 2003 Nov;18(11):741-7.

16. Korinthenberg R, Schessl J, Kirschner J. Clinical presentation and course of childhood Guillain-Barré syndrome: a prospective multicentre study. Neuropediatrics. 2007 Feb;38(1):10-7.

17. Lee JH, Sung IY, Rew IS. Clinical presentation and prognosis of childhood Guillain-Barré syndrome. J Paediatr Child Health. 2008 Jul-Aug;44(7-8):449-54.

18. Ramírez-Zamora M, Burgos-Ganuza CR, Alas-Valle DA, Vergara-Galán PE, Ortez-González Cl. 1Guillain-Barre syndrome in the paediatric age: epidemiological, clinical and therapeutic profile in a hospital in El Salvador. Rev Neurol. 2009 Mar 16-31;48(6):292-6.

19. Hicks CW, Kay B, Worley SE, Moodley M. A clinical picture of Guillain-Barre syndrome in children in the United States. J Child Neurol. 2010 Dec;25(12): 1504-10. Epub 2010 Sep 7.

20. Koul RL, Alfutaisi. A Prospective study of children with Guillian Barre syndrome. Indian J Pediatr 2008 Aug;75(8):787-90.Epub 2008 Jun 25.

21. Sladky JT. Guillain-Barré syndrome in children. 1J Child Neurol. 2004 Mar;19(3):191-200.

22. Ali G, Suleman S. Clinical presentation and outcome of patients presenting with Guillain Barre Syndrome. J Potgrad Med Inst Apr-Jun 2006;20(2):164-9.

23. Sundar U, Abraham E, Gharat A, Yeolekar ME, Trivedi T, Dwivedi N. Neuromuscular respiratory failure in guillain Barre Syndrome:evaluation of clinical and electrodiagnostic predictors. JAPI Sept 2005;53:7648. 


\section{AUTHOR(S):}

1. DR. SOHAIL ASHRAF

M.B.B.S., M.C.P.S., F.C.P.S.

Senior Registrar Pediatrics

Jinnah Medical College and Hospital, Karachi.

\section{DR. ARSHALOOZ J. RAHMAN}

M.B.B.S., D.A.B.P.

Assistant Professor Pediatrics and Child Health

Tha Aga Khan University Hospital, Karachi.

\section{Correspondence Address:}

Dr. Sohail Ashraf

M.B.B.S., M.C.P.S., F.C.P.S.

Senior Registrar Pediatrics

Jinnah Medical College and Hospital, Karachi.

sohailaa2000@yahoo.com

Article received on: 26/11/2012

Accepted for Publication: 15/02/2013

Received after proof reading: 10/03/2013

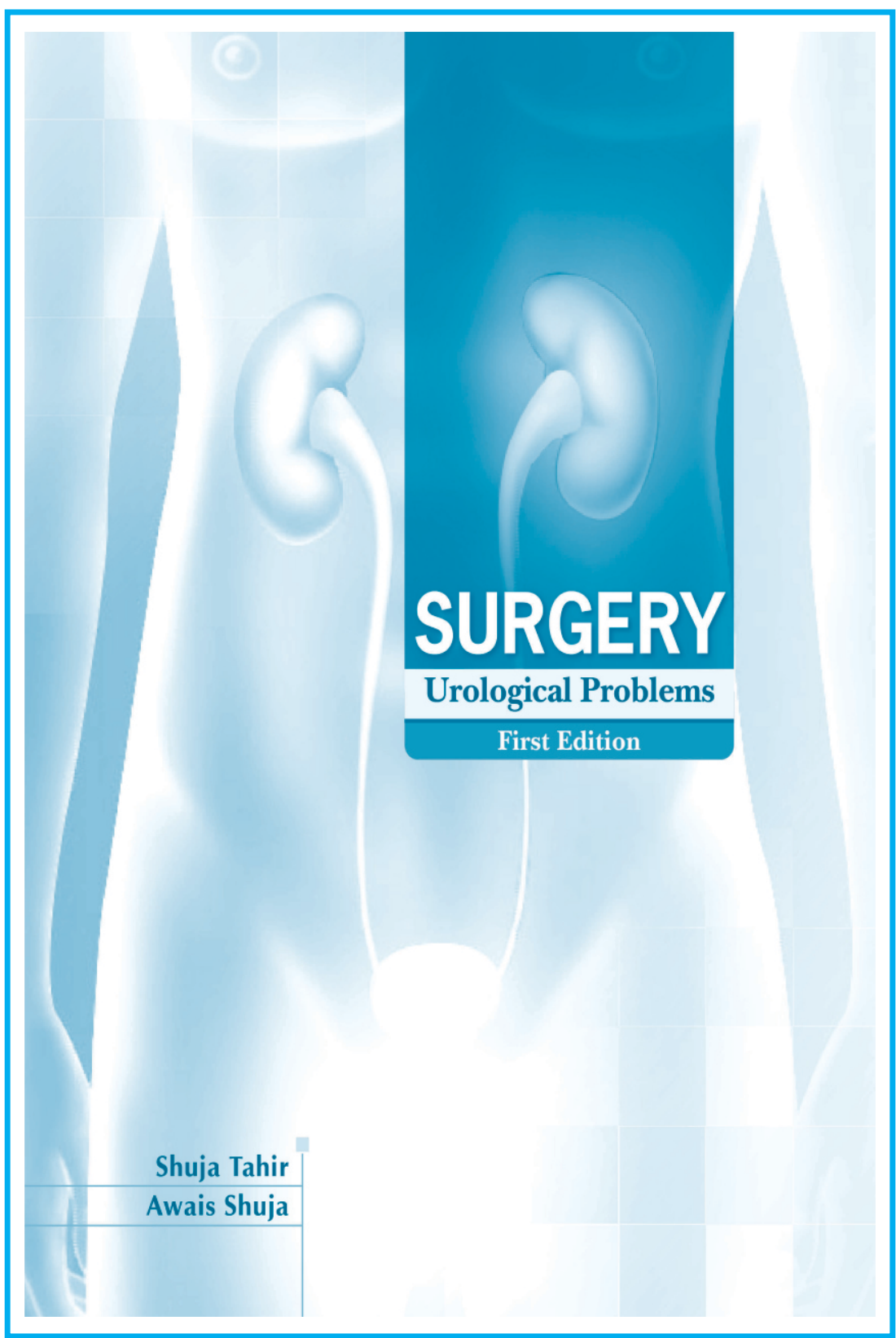

